\title{
Developments and experimental tests on a laboratory-scale drilling automation system
}

\author{
Magomed Khadisov $^{1} \cdot$ Håkon Hagen ${ }^{1} \cdot$ Andreas Jakobsen $^{1} \cdot$ Dan Sui ${ }^{1}$
}

Received: 18 June 2019 / Accepted: 22 August 2019 / Published online: 29 August 2019

(c) The Author(s) 2019

\begin{abstract}
This paper presents the work that has gone into optimizing drilling performances on a laboratory-scale drilling rig, capable of drilling through rock samples in possible shortest time with preventing damages to devices for the sake of drilling costs and safety. The rig is fully functional, and we conducted successful experiments in both manual and autonomous modes. In this study, we focus on testings on drilling optimizations, failures, advancements of understanding of operational limits, and implementations of these boundaries to create a well-designed and controlled drilling rig. Case studies show that good results have been achieved in terms of optimizing drilling parameters and receiving the possible highest drilling speed when drilling different formations.
\end{abstract}

Keywords Drilling rig $\cdot$ Drilling automation $\cdot$ Drilling data $\cdot$ Drilling optimization

\section{Introduction}

In the petroleum industry today, significant resources are invested in research and development on autonomous and intelligent drilling systems, which are capable of quickly and consistently selecting the best course of actions to execute drilling operations. During the drilling processes, unexpected situations typically occur frequently, and because of this, drilling automation systems (Godhavn and Hauge 2018; Godhavn et al. 2011; Hu and Qingyou 2006) need to be highly accurate and reliable as even small faults could escalate to dangerous situations for the personnel, surrounding environment and expensive involved equipment. But how do these systems perform in terms of drilling efficiency compared to conventional drilling procedures? For instance, drilling control systems based on measurements collected through advanced and integrated sensors need to perform time-critical processes to identify drilling problems, optimize drilling operational parameters, make decisions and take actions. Typically, there exist challenges and issues regarding data management and interpretation, computational competence, decision strategies and control

Dan Sui

dan.sui@uis.no

1 Energy and Petroleum Engineering Department, University of Stavanger, Stavanger, Norway algorithms for us to consider in order to improve drilling automation systems. In addition, some trade-offs must be made in consideration of the multi-objective tasks, for example, shall we focus on models or personal's interpretation to react drilling anomalies as fast as possible by lowering reaction and control time, or shall we focus more on searching database of indicators from previously recorded events to identify trends that could indicate an unexpected situation? One might argue that drilling automated systems as we know them today are less effective compared to human-driven operations on a full scale. On the other hand, if a system is to operate manually according to safety regulations, and respond to every indicator of an incident or unexpected situation, this typically also involves a trade-off in terms of what decision is made based on operators' individual experience, skills and personal interpretations.

Since testing and implementing fully autonomous or semi-autonomous drilling solutions on full-scale drilling rigs is not only extremely expensive, but could potentially lead to dangerous situations, small-scale drilling testing rigs provide good solutions to allow engineers and developers to test innovative solutions in a safe and controlled environment. Because the cost of a rather advanced small-scale rig is only a fraction compared to that of a full-scale rig, these small-scale systems could also be used to purposely simulate classical drilling incidents in order to monitor the behavior of the system during drilling operations near the 
absolute limitations of the rig. Therefore, it motivates our study to design, build and test a laboratory-scale drilling rig to resemble a full-scale drilling machine. It has capability to optimize drilling performances, test drilling automation systems and detect and solve several of the typical drilling problems, such as whirl, lateral, torsional and axial vibrations that one would expect to frequently occur during conventional drilling operations. Having such laboratory drilling system helps us to investigate drill string dynamics, rate of penetration (ROP) optimization, bottom hole assembly (BHA)/bit design, software architecture, and control system implementation and tests.

The designed system is equipped with advanced sensors, micro-controllers and control algorithms that can detect, identify and respond to deteriorations in different drilling conditions. The rig is also designed to enter into the international Drillbotics competition hosted by the SPE, in which students are challenged to design and construct autonomous drilling machines to increase the awareness and understanding of how autonomous systems in the future can increase the operational efficiency in the industry and reduce the risk associated with drilling operations. One can find examples of several such autonomous small-scale system designs in Løken et al. (2018, 2019), Bilgesu et al. (2017) and Arnø et al. (2018). These rigs act as an infrastructure to establish multi-disciplinary studies necessary to overcome the challenges related to drilling automation and other advanced drilling technologies.

By implementing the necessary sensors to monitor the rotation system, hoisting system and circulation system of the rig, and testing different drilling strategies, it illustrates that our system not only has the capability to autonomously sweep to the optimal ROP, but also quickly detect, analyze and determine the best solution to allow for a continuous drilling operation without compromising on the ROP. If the system is exposed to a higher rotary speed (RPM) and weight on bit (WOB), the PDC drill bit or other components of the rig are likely to take damages and unexpected drilling problems could be encountered more frequently. Such drilling problems when drilling at a higher WOB and RPM than the founder-point could be extensive vibrations or overtorque in the drill string that ultimately could result in a twist-off of the drill string, thus forcing a shutdown of the system and drilling operation. During experimental tests, the several optimal combinations of RPM and WOB are obtained and compared when drilling different formations, see the case study in "Results and discussion" section. Then the conclusions and future work are provided in the end of the paper.

\section{Drilling rig}

Figures 1 and 2 show the rig and its sketch, respectively. The top drive is controlled by a driver, which allows us to set the RPM and maximum torque that the system can exert. The construction is equipped with a complete hoisting system consisting of actuators, stepper motors and brakes. The top plate is where the top drive and other components are mounted where the top plate is positioned between three triaxial load cells connected to the actuators to provide enough lifting force and for proper stabilization. The brakes have been implemented to be able to stop hoisting/lowering of the top plate if necessary, as well as to reduce the torque on the step motors when the system is not running. To avoid the breaks being mistakenly opened or closed, a solid-state relay opens and closes the breaks simultaneously. Communication between the actuators, brakes, relays and motors is established with the help of the micro-controllers, see more details in "Data acquisition and control systems" section. The circulation system is a simple system consisting of two pumps. Each pump has a maximum flow rate of $19 \mathrm{~L} / \mathrm{min}$ and the maximum working pressure at 3.1 bar. With a plastic hose connected upwards along the rig and through the hollow shaft motor, drill pipe, BHA and exiting through the bit and nozzles out to the bucket system.

The rig, which is superior to the existing solutions/ methods, includes the following sophisticated functions and capabilities:

- conducting vertical/deviated well drilling tests in manual/ autonomous mode;

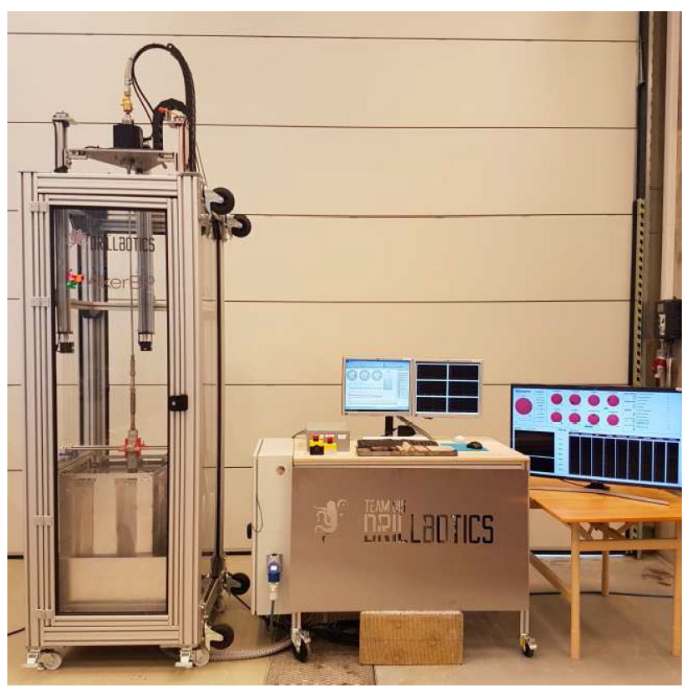

Fig. 1 The laboratory drilling rig 
Fig. 2 Schematics of the rig construction

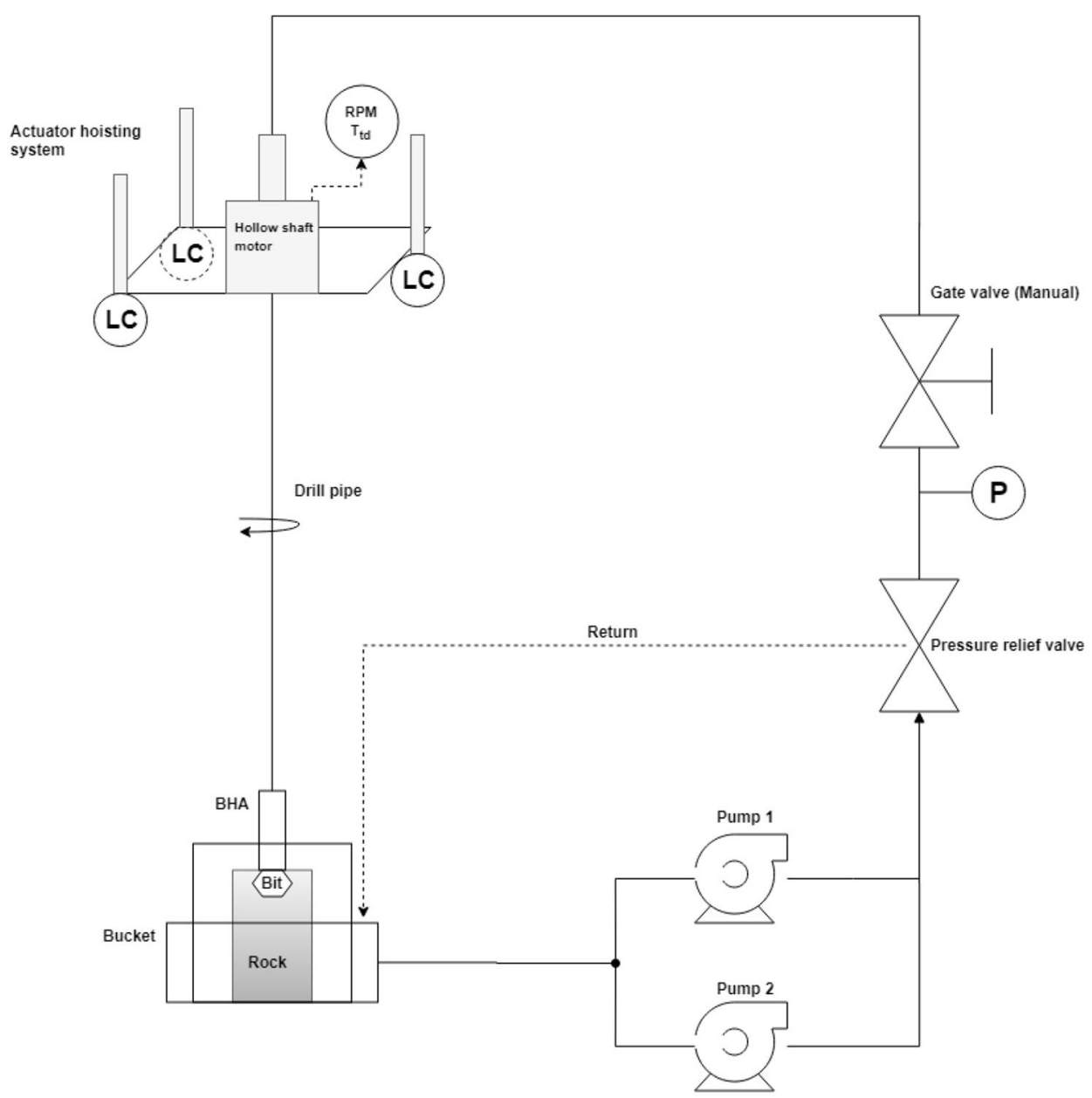

- having a data management system for data processing, analysis, visualization and storage;

- being instrumented with high-speed and reliable downhole and surface sensors;

- having an adaptive advisory system for optimization.

Having such intelligent drilling system allows us to conduct multiple experiments in a laboratory scale with minimum costs and creates possibilities to test and validate the developed data-driven/model-driven approaches. This smart drilling rig is able to identify and react to the common problems occurring during drilling and aid in identification of drilled formations and optimize drilling performances.

\section{Drilling system principle}

In this study, the design considerations, such as using an aluminum pipe with a low yield torque limit making the drill string very susceptible to incidents such as twist-off and buckling have been made to ensure drilling efficiency and safety.

\section{Drill pipe}

The drill pipe is a 6061 T6 aluminum alloy and has the following mechanical properties, see Table 1.

\section{Slenderness}

The slenderness is a measure of the tendency for a drill pipe to buckle. If the slenderness (Eq. 1) is found to be greater than critical ratio (Eq. 5), then it is empirically found that Euler's critical load formula (Eq. 6, Timoshenko and Gere 1961) is applicable.

Slenderness $=\frac{l}{k}$,

and the gyradius, $k$, is defined by

$k=\sqrt{\frac{I}{A}}$ 
Table 1 Drill pipe specifications (Drillbotics) and mechanical properties (ASM-Aerospace Specification Metals Inc.)

\begin{tabular}{ll}
\hline Drill pipe & SI-units $(\mathrm{mm})$ \\
\hline Outer diameter, $D_{\mathrm{o}}$ & 9.525 \\
Wall thickness, WT & 1.245 \\
Inner diameter, $D_{\mathrm{i}}$ & 7.035 \\
Length, $L$ & 921.6 \\
\hline Aluminum alloy & $6061 \mathrm{~T} 6$ \\
\hline Ultimate tensile strength & $310 \mathrm{MPa}$ \\
Tensile yield strength & $276 \mathrm{MPa}$ \\
Modulus of elasticity & $68.9 \mathrm{GPa}$ \\
Ultimate bearing strength & $607 \mathrm{MPa}$ \\
Bearing yield strength & $386 \mathrm{MPa}$ \\
Poisson's ratio & 0.33 \\
Shear modulus & $26 \mathrm{GPa}$ \\
Shear strength & $207 \mathrm{MPa}$ \\
\hline
\end{tabular}

Table 2 Results on slenderness and load calculations

\begin{tabular}{ll}
\hline Cross-sectional area, $A$ & $3.24 \times 10^{-6} \mathrm{~m}^{2}$ \\
Second moment area, $I$ & $2.84 \times 10^{-10} \mathrm{~m}^{4}$ \\
Critical slenderness ratio & 70.2 \\
Slenderness ratio of drill pipe & 280.2 \\
Modulus of elasticity, $E$ & $68.9 \times 10^{9} \mathrm{~Pa}$ \\
Second moment area, $I$ & $2.84 \times 10^{-10} \mathrm{~m}^{4}$ \\
Effective length factor, $K$ & 0.9 \\
Original length of pipe, $L$ & $0.9216 \mathrm{~m}$ \\
Euler's critical load, $F_{\mathrm{Cr}}$ & $280.5 \mathrm{~N}$ \\
\hline
\end{tabular}

where $I$ is the minimum moment area of the cross-section and $A$ is the cross-sectional area, given by Eqs. 3 and 4, respectively.

$I=\frac{\pi}{64}\left(D_{\mathrm{o}}^{4}-D_{\mathrm{i}}^{4}\right)$,

$A=\frac{\pi}{4}\left(D_{\mathrm{o}}^{2}-D_{\mathrm{i}}^{2}\right)$,

where $D_{\mathrm{o}}$ and $D_{\mathrm{i}}$ are outer diameter and inner diameters, respectively. The critical slenderness ratio is given as follows

$\left(\frac{l}{k}\right)_{\mathrm{Cr}}=\sqrt{\frac{2 \pi^{2} E}{\sigma_{y}}}$,

where $E$ is the modulus of elasticity and $\sigma_{y}$ is the tensile yield strength. Inputting the values listed in Table 1 into the formulas above, we get the following results shown in Table 2. As a result, the slenderness ratio of our drill pipe is much greater than the critical slenderness ratio,
$280.2>70.2$, which means that the Euler's critical load formula is applicable for further calculations on buckling.

\section{Buckling}

Buckling of a drill pipe is the main limiting factor when it comes to selecting a maximum WOB. Due to the thin aluminum drill pipe, it was expected that it would easily buckle if the WOB was set too high. Buckling occurs when a structure, such as a drill pipe, is subjected to compressive stress and start a sideways deflection. The deflection may cause the drill pipe to rapidly wear due to abrasion along the borehole wall. If the deflection becomes too great, the drill pipe will start to deform plastically and eventually loose all its load-bearing capacity. In order to prevent the buckling effect, it is important to know the strength of the drill pipe by using Euler's critical load formula given below

$F_{\mathrm{Cr}}=\frac{\pi^{2} E I}{(K L)^{2}}$,

where $K$ is column effective length factor and $L$ is the unsupported length of the column. The input data and result for Euler's critical load formula can then be found in Table 2. The critical load was found to be $280.5 \mathrm{~N}$. Thus, one should not apply more than $280.5 \mathrm{~N}$ of the WOB to avoid the drill pipe from buckling.

\section{Maximum torque}

In our case, torsional vibrations might be the most critical reason leading to drilling failures. Torsional vibrations are typically caused by stick-slips that make the drill bit stop rotating and make the drill string accelerate and decelerate in a periodic manner. Then, it is important to know how much torque the drill pipe can endure in order to prevent it from failures. One can calculate the maximum torque using Eq. 7:

$T=\tau \frac{J}{\rho_{\mathrm{r}}}$,

where $T$ is the torque, $\tau$ is the shear stress, $J$ is the polar moment of inertia, and $\rho_{\mathrm{r}}$ is the radial distance to center of the pipe. From the above equation, it is easy to get the maximum torque:

$T_{\mathrm{Max}}=\tau_{\mathrm{Max}} \frac{\pi}{16}\left(\frac{D_{\mathrm{o}}^{4}-D_{\mathrm{i}}^{4}}{D_{\mathrm{o}}}\right)$,

where $\tau_{\text {Max }}$ is the maximum shear stress. The shear strength of aluminum alloy $6061 \mathrm{~T} 6$, shown in Table 1, is set to be the maximum shear stress, $\tau_{\mathrm{Max}}$ which the aluminum pipe can endure before shearing. By inputting data from Table 1, 
one can calculate that the maximum torque applied before the pipe shears is:

$T_{\text {Max }}=24.7 \mathrm{Nm}$.

In order to perform safe drilling, one should also know the shear yield strength, $\tau_{y}$. By using Euler-Mascheroni constant of 0.577 , one can convert tensile yield strength, $\sigma_{y}$, to shear yield strength, $\tau_{y}$, as shown in Eq. 10.

$\tau_{y}=0.577 \sigma_{y}$.

This leads to a shear yield strength of $\tau_{y}=0.577 \times 276 \mathrm{MPa}=159.3 \mathrm{MPa}$, and by using Eq. 8 gives the maximum torque applied before the pipe yields to be:

$T_{y}=\tau_{y} \frac{\pi}{16}\left(\frac{D_{\mathrm{o}}^{4}-D_{\mathrm{i}}^{4}}{D_{\mathrm{o}}}\right)=19.0 \mathrm{Nm}$.

The results imply that the top drive motor should have a theoretical maximum operating limit of $19.0 \mathrm{Nm}$ and should never exceed $24.7 \mathrm{Nm}$ of torque.

\section{Pressure}

The main purpose of a circulation system is the transportation of cuttings, lubrication and cooling of the bit. For our system, no kick/loss situation is considered for the sake of drilling rock samples. Fresh water is selected at this scale for HSE issues. Pressure loss in the hose, the pipe and the BHA part can be calculated below:

$\Delta P_{\mathrm{F}}=\frac{1}{2} \rho f_{\mathrm{D}} u^{2} \frac{L}{D_{\mathrm{i}}}$,

where $L$ equals the length of the hose, $\rho$ is the fluid density, $u$ is the velocity of the liquid inside the hose, and $f_{\mathrm{D}}$ is the friction factor. Pressure loss in the drill bit does not primarily come from friction forces, but more from the acceleration of the drilling fluid through the bit nozzles. The bit pressure drop is expressed as (Bourgoyne 1986)

$\Delta P_{\mathrm{bit}}=\frac{\rho Q^{2}}{12.031 A_{\mathrm{T}}^{2} C_{\mathrm{d}}^{2}}$,

where $C_{\mathrm{d}}$ is the dimensionless nozzle discharge coefficient which is set to 0.95 as a general rule, $Q$ is flow rate, and $A_{\mathrm{T}}$ is total nozzle area. For the swivel, we use following formula given in Akisanmi (2016) to calculate pressure loss:

$\Delta P_{\text {swivel }}=\frac{\rho Q^{2}}{A^{2} C_{\mathrm{v}}^{2}}$,

where $C_{v}$ is the flow coefficient. The pressure loss for each part and total one are given in Table 3.
Table 3 Calculated pressure loss at $11 \mathrm{~L} / \mathrm{min}$

\begin{tabular}{ll}
\hline Part & $\Delta \mathrm{P}($ bar $)$ \\
\hline Hydrostatic & 0.235 \\
Hose & 0.009 \\
Drillpipe & 0.301 \\
Nozzles & 2.470 \\
BHA & 1.411 \\
Swivel & 0.021 \\
Total & 4.507 \\
\hline
\end{tabular}

\section{Mechanical specific energy}

Mechanical specific energy (MSE) (Losoya et al. 2018) is the energy required by a drill bit to remove a unit of volume of rocks. The concept gives a fair indication on how effective the drilling process is. If the rock is broken into smaller fragments than necessary, this will lead to more energy usage than required. The opposite being, if the rock fragments are too large, this will also lead to more energy usage, making it necessary to break the fragments into smaller pieces.

MSE $=\frac{\text { Total Energy Input }}{\text { Volume Removed }}$.

The above equation can be transformed to a more practical formula as

MSE $=\frac{\text { Volume Energy Input }}{\text { Volume Removed }}+\frac{\text { Rotational Energy Input }}{\text { Volume Removed }}$

or

$\mathrm{MSE}=\frac{\mathrm{WOB}}{\text { Area }}+\frac{2 \pi \cdot \mathrm{RPM} \cdot T}{\mathrm{Area} \cdot \mathrm{ROP}}$.

To achieve the optimal drilling efficiency, the objective is to minimize the MSE or to maximize the ROP. The MSE can be minimized by adjusting the set-points of the WOB, the ROP and the RPM in consideration of other factors, like wellbore stability, cuttings transport and drilling safety.

\section{Data acquisition and control systems}

\section{Sensors}

\section{Surface sensors}

With the main task of developing an autonomous drilling rig, sensor implementation is an area that has received a lot of attention. The computer relies on good data from sensors implemented to make decisions and provide users with valuable information. Our drilling rig system has a total of 17 sensors, including three load cells capable of providing 
measurements for $x$-, $y$ - and $z$-axis; two torque sensors, one integrated in the top drive and one external for torque measurement at the top of the drill string; and in addition a RPM encoder (in the top drive).

\section{Downhole sensors}

The design, manufacturing and implementation of a downhole measurement tool including accelerometer, gyroscope and magnetometer have also been conducted in our work. The key focused area is data transmission and real-time calculations. Drill string vibration is a complex phenomenon that often results in non-productive time. The complexity lies in the coupled action of the three vibrational modes: axial, lateral and torsional. The modes excite one another, which makes it difficult to recognize a particular mode and prevent destructive vibrations. A downhole measurement system allows us to capture the moment when vibrations occur and adjust operational parameters (the WOB and the RPM) in real time to mitigate damages to the string components. The other function of downhole measurement is to do the bit position tracking and control. Besides them, another important function is to record and keep the data to do a post-analysis to determine the following:

- natural frequency of the system under various loads and rotational speeds,

- what mode of vibrations is dominant for particular operational conditions,

- what is the magnitude of loads the BHA and the bit are exposed to during drilling,

- how the system responds to initial conditions and no-load condition, i.e., external forces are equal to zero,

- system's transient response to external loads.

The electronics are sealed by using O-rings which press against the inner wall of the stabilizer sleeve as shown in Fig. 3.

\section{Data acquisition system}

Data acquisition (DAQ) is the process of measuring and communicating electrical or physical phenomenons such as voltage, current, pressure or temperature with sensors, communication devices and computes. A DAQ system consists of sensors, hardware and software which often come with the DAQ-device. A simple setup of a DAQ system would be a sensor sending analog signals to the DAQdevice, where the signals are converted to digital signals, and/or sent for signal conditioning, see Fig. 4 that shows how the drilling measurement is communicated through the DAQ system. From the DAQ-device, the signals are

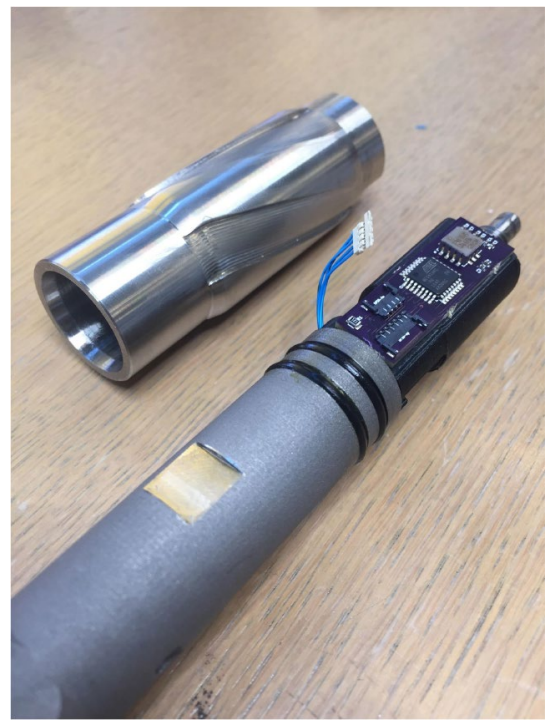

Fig. 3 Downhole sensors in the BHA

sent to the micro-controllers (Arduino Duo) using a data bus, which is a set of connectors or a set of wires.

The DAQ system in our study is the QuantumX (https ://www.hbm.com/en/2128/quantumx-compact-universaldata-acquisition-system/) with 8 connectors per module. The sensors and transducers based on 17 different sensor technologies can be connected to each of the 8 channels on these amplifiers. The module provides us with a 24-bit analog to digital converter, with sampling rates of $40 \mathrm{ks} / \mathrm{s}$ (kilo samples per second) per channel, and active lowpass filters (moving average filter) that are renowned for their high precision. It is to receive data of higher quality from the system and ensures that we have the necessary amplifying capacity.

\section{Control system}

The proposed control system hierarchy includes synchronized interconnected communication between the microcontrollers, see Fig. 4. The load cells are capable of giving readings from all the three axes, although only the $z$-axis signals are used for controlling the WOB. Other sensors connected to the QuantumX module are:

- top drive encoder - providing us with values for the RPM and the torque,

- height sensor that has higher accuracy,

- torque measurements from the bit and drill string (downhole sensors).

Figure 4 shows the complete overview of the control system, with integrated DAQ-module, providing us with highquality data for the real-time data management. To control 
Fig. 4 Overview of the control system hierarchy

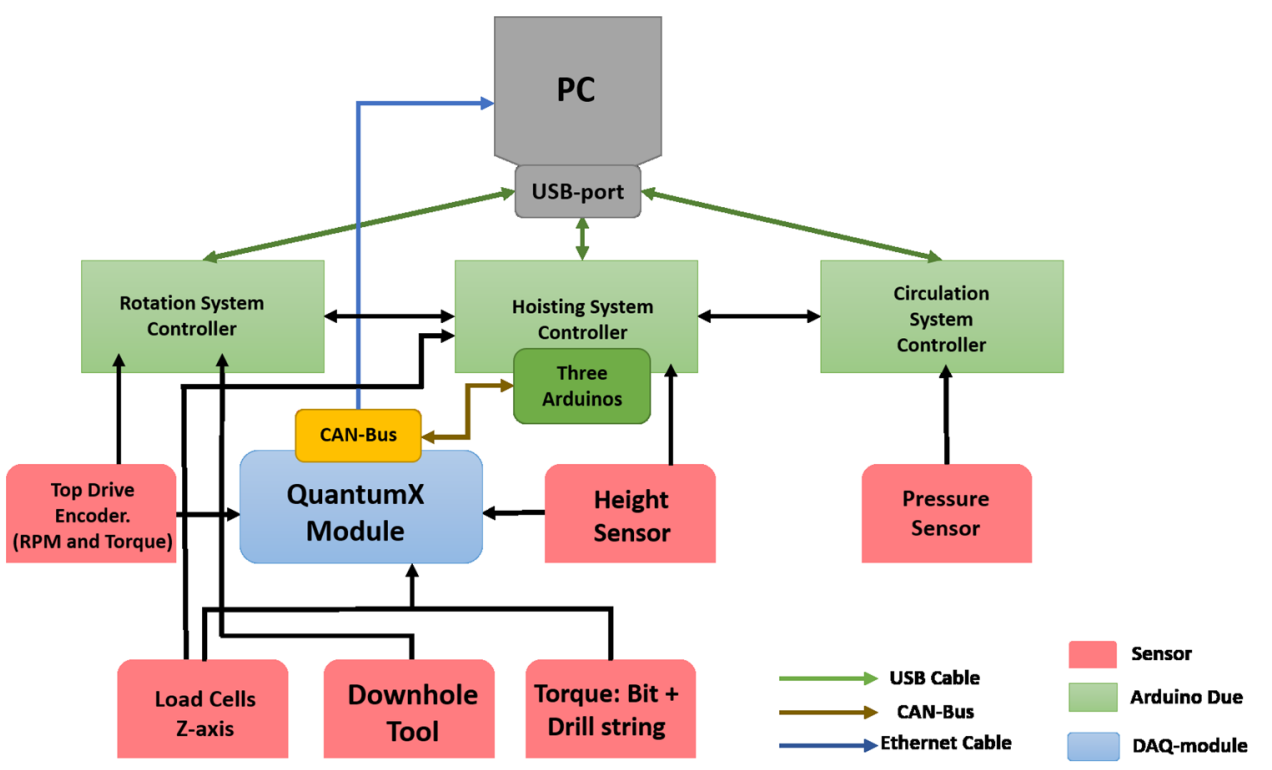

the WOB, three actuators are individually controlled using a proportional integral derivative (PID) controller (Ang et al. 2005), where the set-points of the WOB and the RPM are provided by users in manual mode or by the ROP optimization algorithms in autonomous mode.

\section{Results and discussion}

In this section, we drilled two different rock samples, chalk and concrete to test the drilling performances running in both manual mode and autonomous mode. The purpose of doing them is to seek for the best combinations of drilling parameters for the high ROP or the low MSE and in the meanwhile for reducing drilling incidents with respect to different formations. Also during manual operations, good experiences, observations, knowledge and lessons are obtained for developing and improving the control algorithms for automated operations.

\section{Chalk}

\section{Well Chalk 1: performing autonomous drilling}

Well Chalk 1 was drilled in autonomous mode where the system was self-driven by designed control system and DAQ without human interaction. This was to see how the system behaves when drilling in a soft formations. Well Chalk 1 is approximately $19 \mathrm{~cm}$ in depth and was characterized by the substantial amount of vibrations and the low drilling efficiency. Data for the well are presented in Fig. 5. The calculated MSE is high, indicating that the drilling efficiency is low and a lot of energy was wasted.
The autonomous mode kept a constant WOB of $1 \mathrm{~kg}$ and the increased RPM throughout the process before staying constant at a RPM of 800 . The system was able to achieve an acceptable ROP of $2.2-2.4 \mathrm{~cm} / \mathrm{min}$, but the high ROP does not necessary mean efficient drilling. This well illustrated it perfectly. The heavy lateral vibration was introduced when the RPM was increased, which led to the diameter of the well being greater than the diameter of the bit (a well hole diameter that was 50\% larger than the diameter of the bit). Equation 17 assumes that the area drilled is a function of bit diameter, which was not the case. It means we drilled a well with greater diameter than necessary leading to energy waste. The test was successful and pinpointed that the operational parameters like the WOB and the RPM in autonomous mode need to be further optimized for soft formations.

\section{Well Chalk 2: performing manual drilling varying RPM}

Well Chalk 2 was drilled manually with the main goal of identifying which combination of parameters resulted in the high ROP, where the set-points of the WOB and the RPM were offered by operators. During this case, we mainly focused on varying the RPM and keeping the WOB constant. What we found was that we had the same ROP at 300 RPM and 1400 RPM. The difference is the higher RPM resulting in vibrations when combined with the lower WOB. We concluded that the lower RPM can yield the same ROP as the higher RPM, while the high RPM just introduced heavy lateral vibrations, which leads to higher and inaccurate values (larger hole size) for the MSE, see Fig. 6. 
Well 1 , Chalk

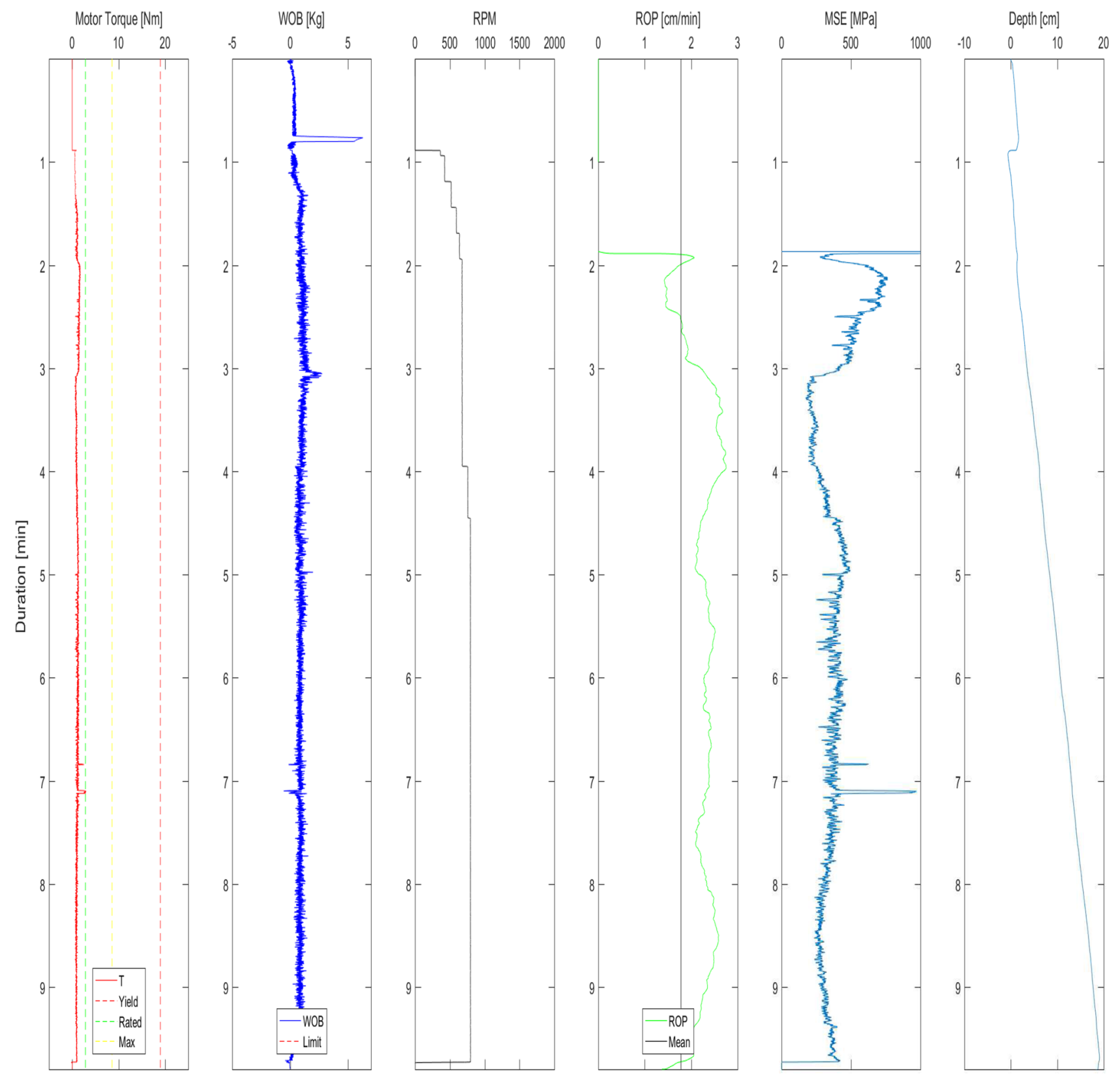

Fig. 5 Well Chalk 1, result of lateral vibrations

Well Chalk 3: performing manual drilling with optimal RPM

We set the RPM at 300 which was sufficient for soft formations. Figure 7 shows the success of this well. At a depth of $2.5 \mathrm{~cm}$, we had the WOB around $1.3 \mathrm{~kg}$ with a corresponding ROP of $2.1 \mathrm{~cm} / \mathrm{min}$. The MSE at this depth was also close to the 5-25 MPa range for the chalk. What we observed after post-analysis of the data was that a WOB of $4 \mathrm{~kg}$ combined with $300 \mathrm{RPM}$ had good results, with a ROP of $2.4-2.5 \mathrm{~cm} / \mathrm{min}$. Well Chalk 3 showed that soft formation does not require the RPM over 500, but a higher WOB is optimal. This information can be used for optimizing the autonomous drilling mode. Well Chalk 3 presented us also bit balling phenomena, see Fig. 8. Bit balling can be mitigated by increasing the RPM and flow rate and lowering the WOB. Considering this test was characterized by the low RPM and the high WOB, bit balling has to be expected drilling in formations such as clay or chalk. This incident of bit balling was caused by the chalk turning into a thick viscous paste that increased the surface 
Well 2, Chalk

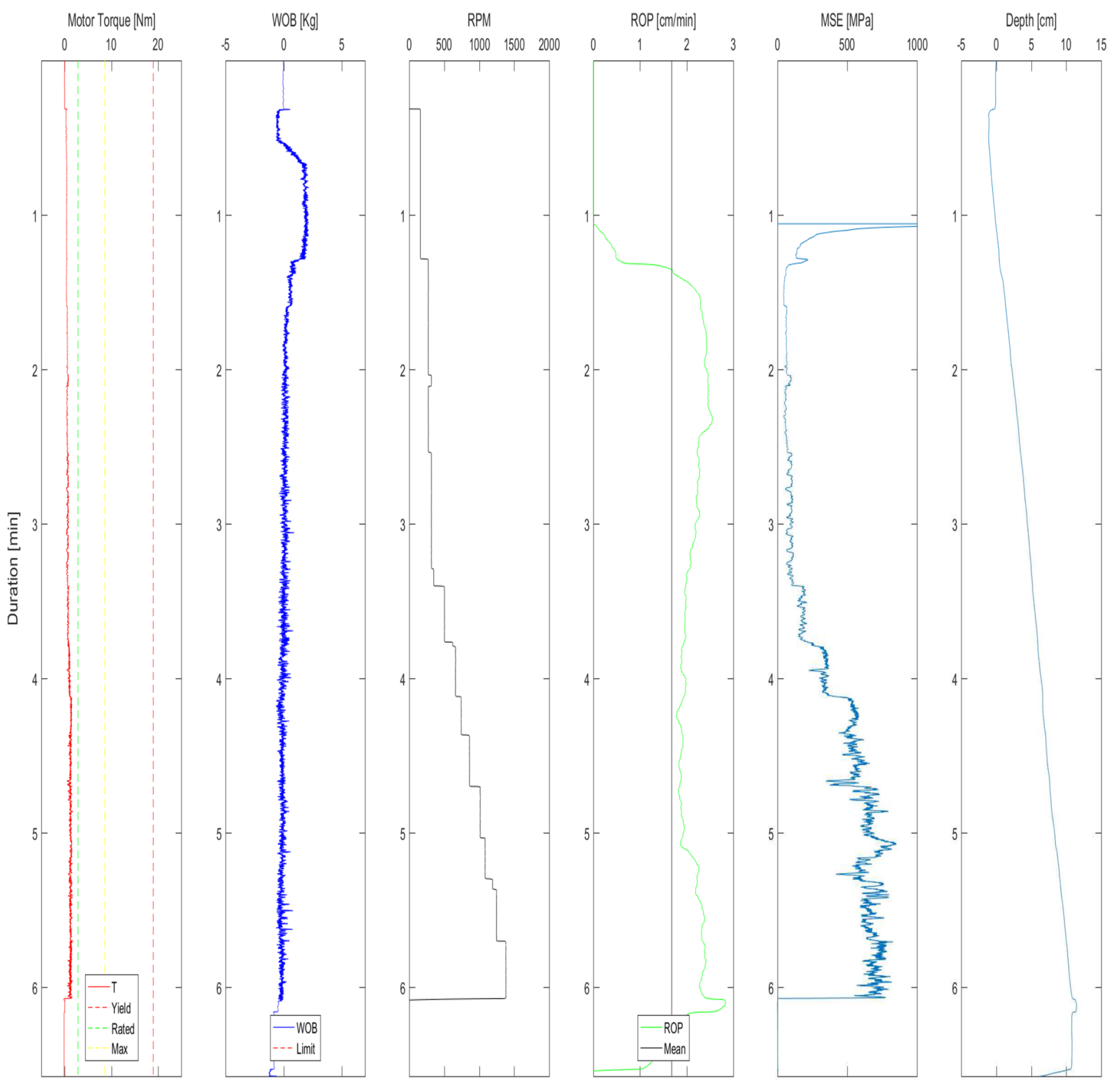

Fig. 6 Well Chalk 2, manual mode with varying RPM

friction. After the drilling was completed and the BHA was lifted out, we also noticed that one of the nozzles was plugged and that the paste had worked its way up the bit. A more efficient and powerful circulation system could be implemented to avoid bit balling.

\section{Discussions}

Drilling of the chalk samples was a successful test. From Well Chalk 1 to Well Chalk 3, we are able to identify what combination of parameters yielded the highest ROP. We have already mentioned that a WOB of $4 \mathrm{~kg}$ and 300 RPM seem to be the best solution when drilling in the soft formation. This mitigates the introduction of vibrations, resulting in high drilling efficiency and respectable values for the MSE. These findings can be used to tune the autonomous drilling mode when the system detects that it is drilling in a soft formation. Without the implementation of rock classification/detection while drilling, tuning the autonomous mode to keep the low RPM will give us 
Well 3, Chalk
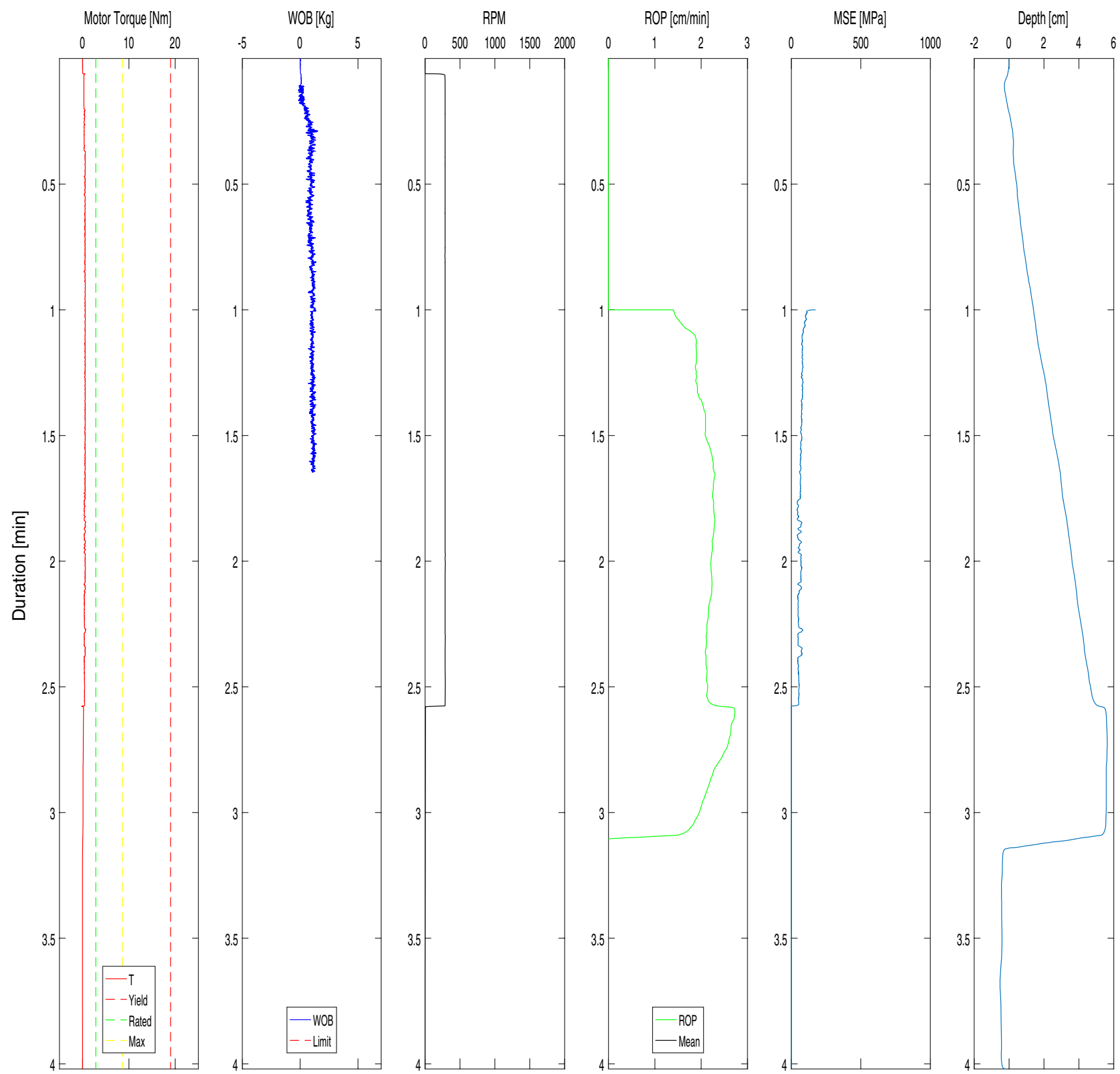

Fig. 7 Well Chalk 3, manual mode with varying WOB

bad results when drilling in a multilayered formation with varying hardness. With this test, we are also able to conclude that the MSE equation yields correct values for the MSE values, given that the drilling is efficient and energy is not wasted as vibrations happen.

\section{Concrete}

The concrete rock sample consisted of Portland cement and quartz sand with a diameter of less than $8 \mathrm{~mm}$. The longest well which could be drilled was $15 \mathrm{~cm}$ due to the size of the concrete sample. Four wells were drilled manually using multiple variations of the WOB and the RPM and one well was drilled in autonomous mode to compare manual and autonomous drilling, see Fig. 9 for such 5 drilled wells.

Well Concrete 1: WOB control set to $2 \mathrm{~kg}$ and varying RPM

Well Concrete 1 was drilled with the intent of finding the RPM which yielded the highest ROP. The WOB control 
Fig. 8 From left: Plugged nozzle, bit balling paste, well hole diameter being on gauge with bit diameter

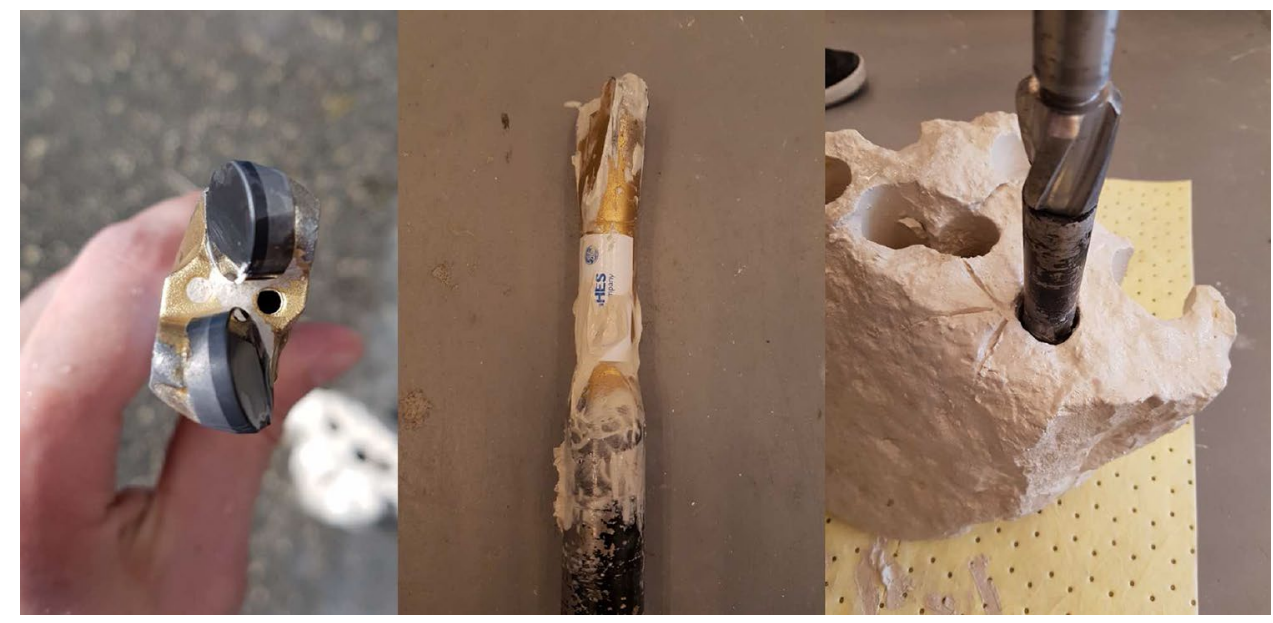

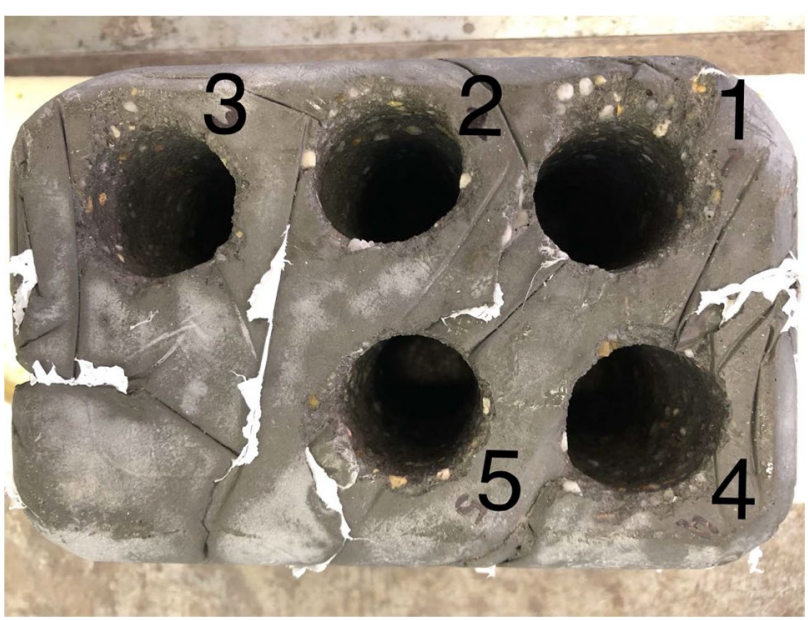

Fig. 9 Five wells drilled in concrete with different parameter configurations

was set to have a fixed value of $2 \mathrm{~kg}$, while the RPM was manually increased from 300 to 1400 RPM with the certain increments. From Fig. 10, it was observed that the WOB was not held constant. The WOB was gradually decreasing from approximately $4 \mathrm{~kg}$ WOB to $2 \mathrm{~kg}$ WOB. This means the WOB PID control had some difficulties trying to obtain the desired set-point which caused the large fluctuations on the WOB. Good WOB control is depended on a well-tuned PID controller, which is a difficult task due to a heavily vibrating environment.

Analyzing the data from Well Concrete 1 leads to three selected values for the RPM which were interesting to investigate further. The selection was based on the ROP performance. If the ROP was approximately the same for the higher RPM as for the lower RPM, the lower RPM was preferred. This is due to a lower chance of an incident like twist-off, damaging vibrations, whirl or stick-slip and the fault detection system has a greater chance to do remedial actions. The optimal ROP was approximately $2 \mathrm{~cm} / \mathrm{min}$.
Well Concrete 1 was drilled with the fairly low WOB compared to what the system can handle. From the experiment, it was concluded that the ROP does not necessarily increase with the higher RPM and the best RPM for Well Concrete 1 was in the range 600-1000 RPM.

\section{Well Concrete 2: constant 680 RPM and varying WOB}

As observed in Well Concrete 1, we experienced that 680 RPM is a good value for the optimal RPM. The setup for this drilling experiment was to set the desired RPM, and then the WOB was increased with $1 \mathrm{~kg}$ after the certain time interval to analyse the ROP behavior at the different WOB set-points.

A continuing issue for drilling these wells was the WOB control, mainly due to the heavily vibrating environment. The vibrations cause the system to misinterpret the load cell measurements for the actual WOB, making a continuous WOB set-point difficult. Even though the WOB data are very fluctuating, some valuable results were fortunately achieved. As the WOB increases, the ROP increases relatively proportionally. This can be seen in Fig. 11. After approximately 3.5 min of drilling, the ROP seems to go from rapid increasing to slow increasing. An explanation for this might be that the WOB did not increase according to the WOB set-points. Due to the fluctuations, it can be hard to interpret the WOB, but by examining the well log one can see that the WOB does not increase considerately after $3.5 \mathrm{~min}$. Although the WOB data are not perfect, Fig. 11 clearly shows in what range the ROP was the highest. After about $3.5 \mathrm{~min}$ of drilling until the drilling was finished, a high and relatively stable ROP was observed. In this region, one can indicate a moderate increase in the ROP.

As seen from Fig. 11, the WOB varies from approximately $3.9-4.5 \mathrm{~kg}$ for the optimal ROP region. Since a moderate increase in the ROP is confirmed in this region, one might expect even the higher ROP at the higher WOB. Regarding the MSE calculations, the MSE is within the

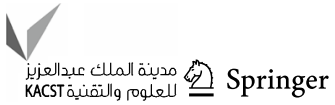


Well 1, Concrete

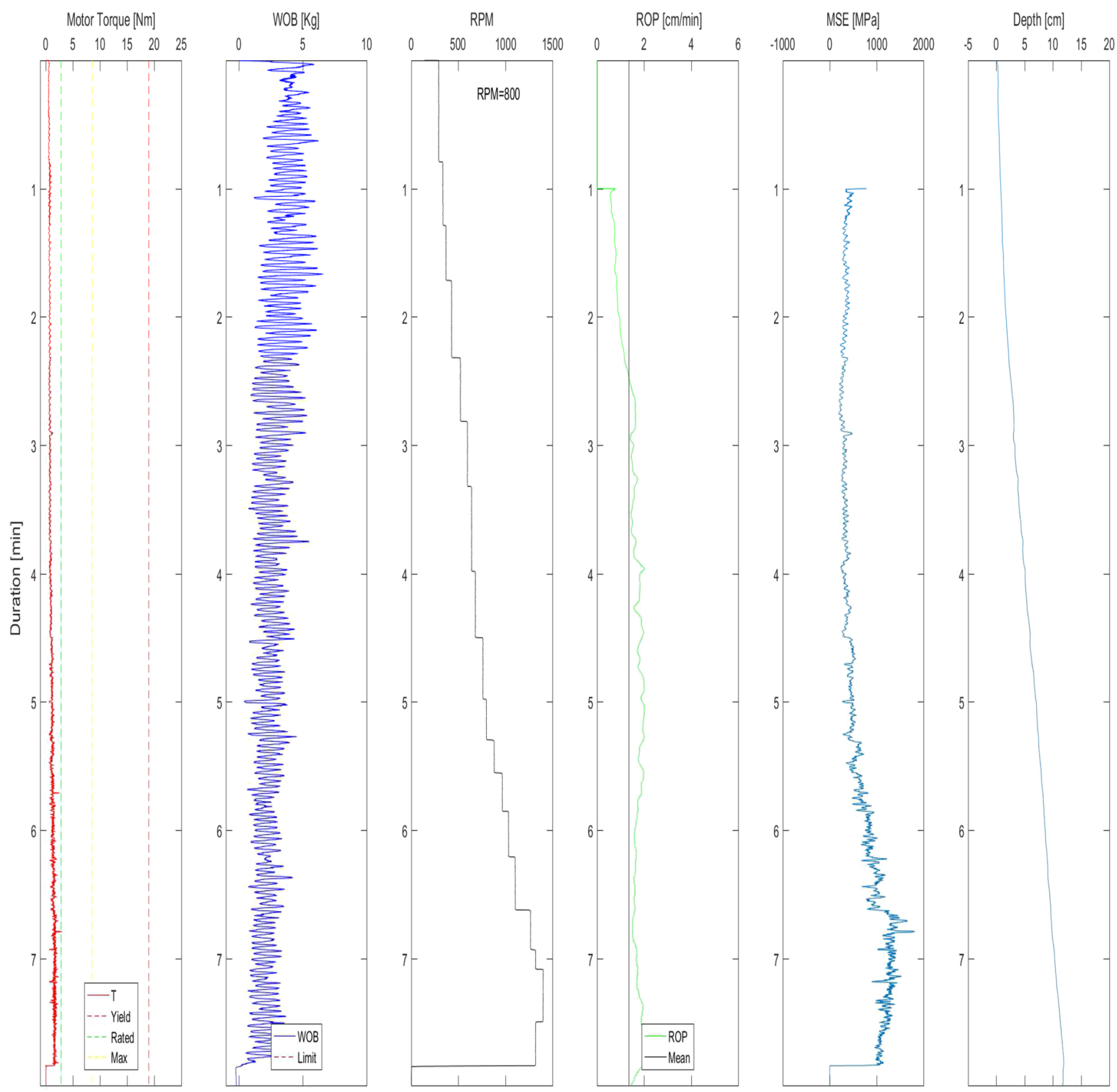

Fig. 10 Well Concrete 1, manual mode with varying RPM

respective range for the concrete. This shows good drilling efficiency, meaning a big portion of the energy input was used for actual drilling. The well quality was also observed to be good.

\section{Well Concrete 3: constant 800 RPM and varying WOB}

Well Concrete 3 was drilled in a similar manner as Well Concrete 2, only with the higher RPM. The RPM for this well was fixed at 800 RPM throughout the well, varying the WOB with increments of $1 \mathrm{~kg}$. The data are presented in Fig. 12. As mentioned earlier, the WOB signals are with high fluctuations. Even though the WOB data are not good enough, the WOB was better on Well Concrete 3 than Well Concrete 2. For Well Concrete 3, one can see the WOB gradually increasing as desired and it interacts with the ROP values. The ROP is constantly increasing with increasing WOB. Rather than having a region where the ROP is more or less the same, one now has a point where the ROP abruptly decreases because of ended drilling process. This is 
Well 2, Concrete
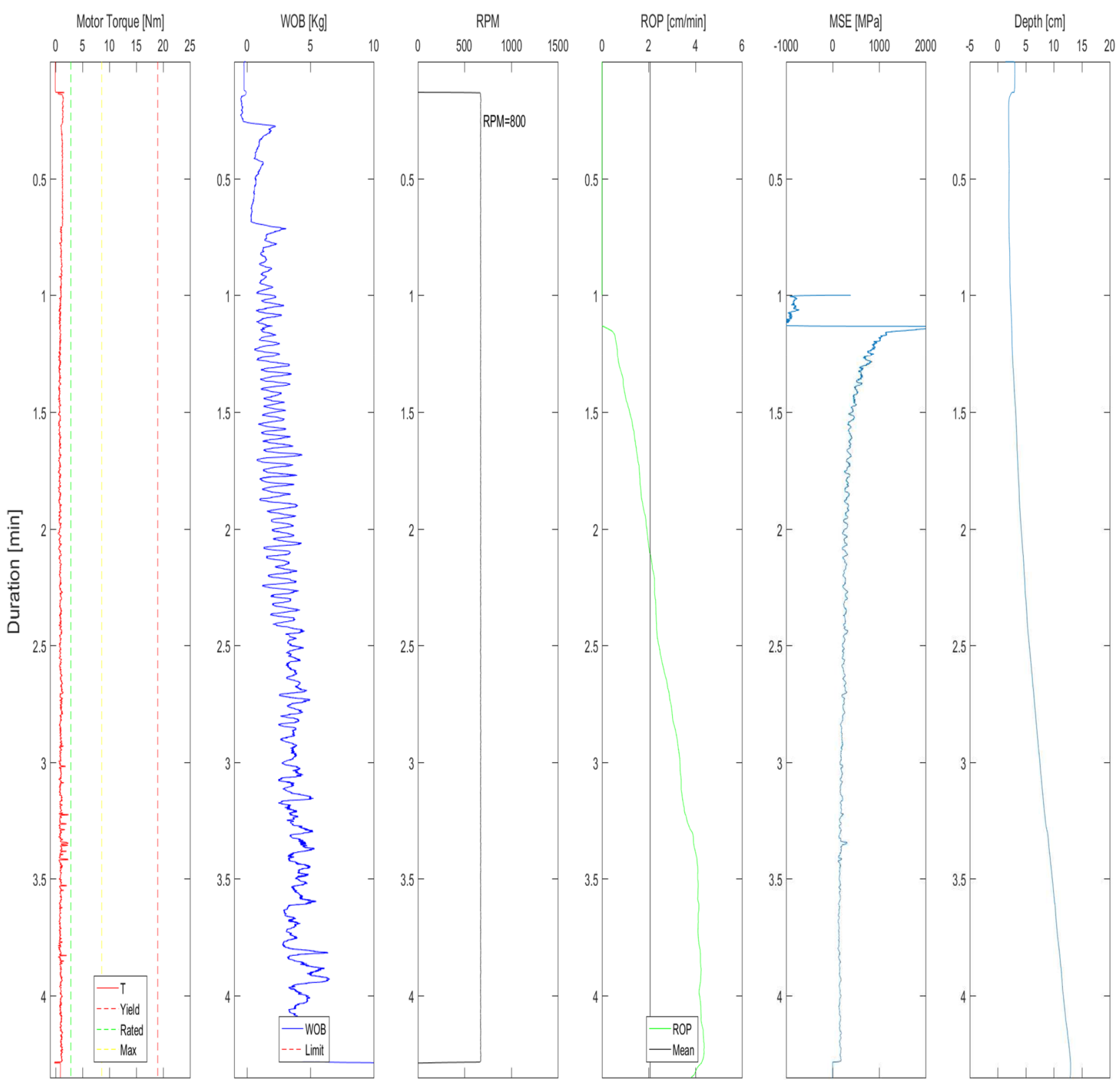

Fig. 11 Well Concrete 2, manual mode with varying $\mathrm{WOB}, \mathrm{RPM}=680$

an indication that further increase in the WOB would result in even the higher ROP.

The maximum ROP is 6.4 times greater than the minimal with the same RPM. This also highly affects the MSE. From Fig. 12, one can clearly see the substantially lower MSE where the ROP is at its maximum compared to its minimum, which can be interpreted as better drilling efficiency.

\section{Well Concrete 4: constant 960 RPM and varying WOB}

Similar to Well Concretes 2 and 3, Well Concrete 4 was drilled with the varying WOB and the constant RPM except from the short increase in the RPM at the end of the well. Data from Well Concrete 4 can be seen in Fig. 13. One can observe that the optimal ROP is within a region, where the ROP is more or less the same even though the WOB was increased. This indicates that increasing the WOB does not necessarily lead to a higher ROP for this fixed RPM. 
Well 3, Concrete

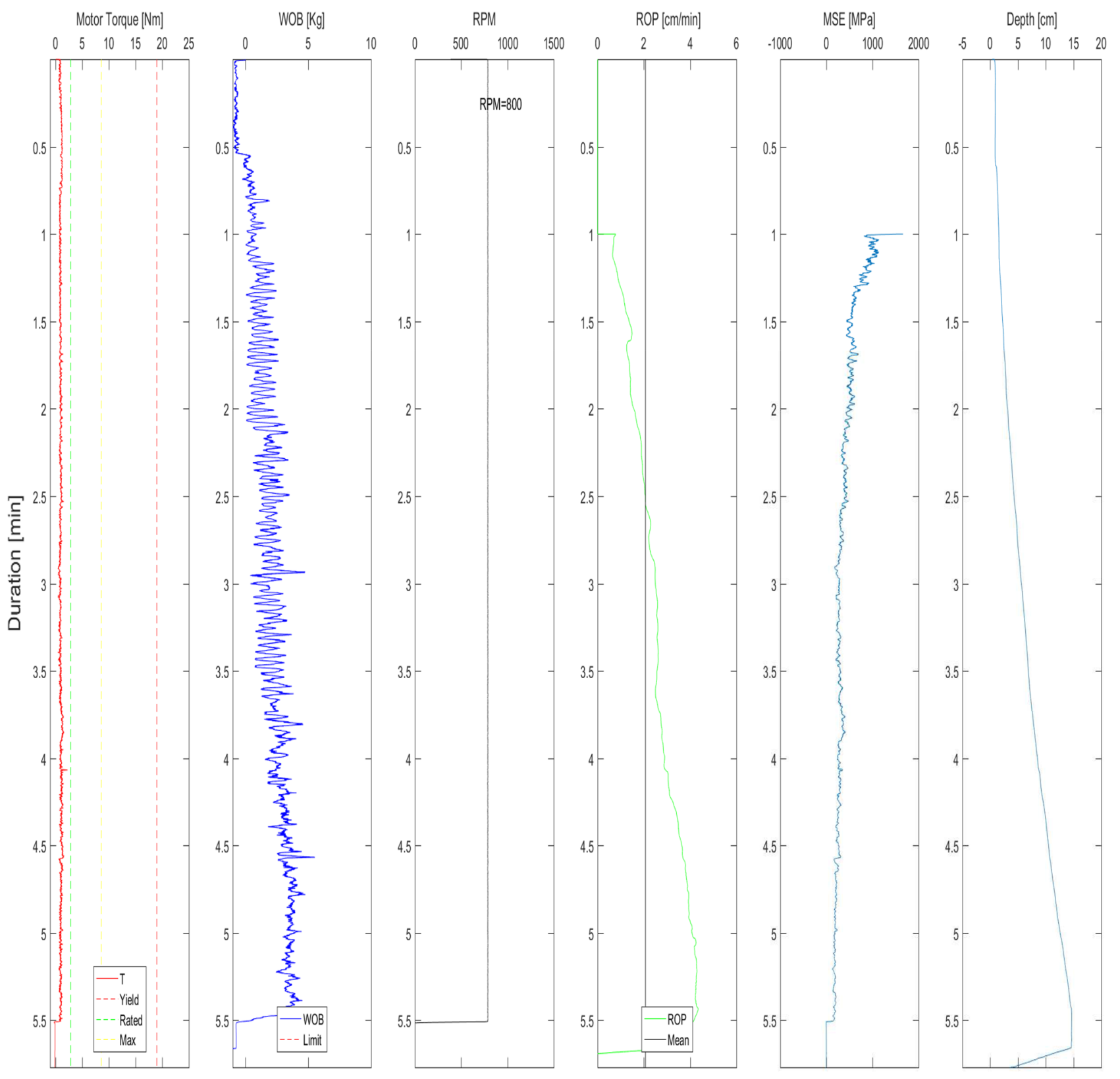

Fig. 12 Well Concrete 3, manual mode with varying WOB $(\mathrm{RPM}=800)$

One can see that the ROP is more or less the same with $3.9 \mathrm{~kg}$ WOB and $4.5 \mathrm{~kg}$ WOB. In addition, increasing the RPM does not seem to have any substantial effect on the ROP either. As mentioned, the MSE values give good indications of drilling efficiency. From Fig. 13, one can observe that the MSEs have the lowest values when the RPM is 960 and the WOB is $4.5 \mathrm{~kg}$.

\section{Well Concrete 5: autonomous drilling}

The last well was drilled using the autonomous drilling mode. It tried to optimize the ROP as soon as it is in contact with the formation, increasing either the RPM or the WOB based on optimization algorithms every $15 \mathrm{~s}$. The system quickly increased the RPM and was content with the lower WOB to create a stable pilot hole. At 636 RPM, the system has reached a rotational speed high enough to remove the formation near the bit. To further increase the 


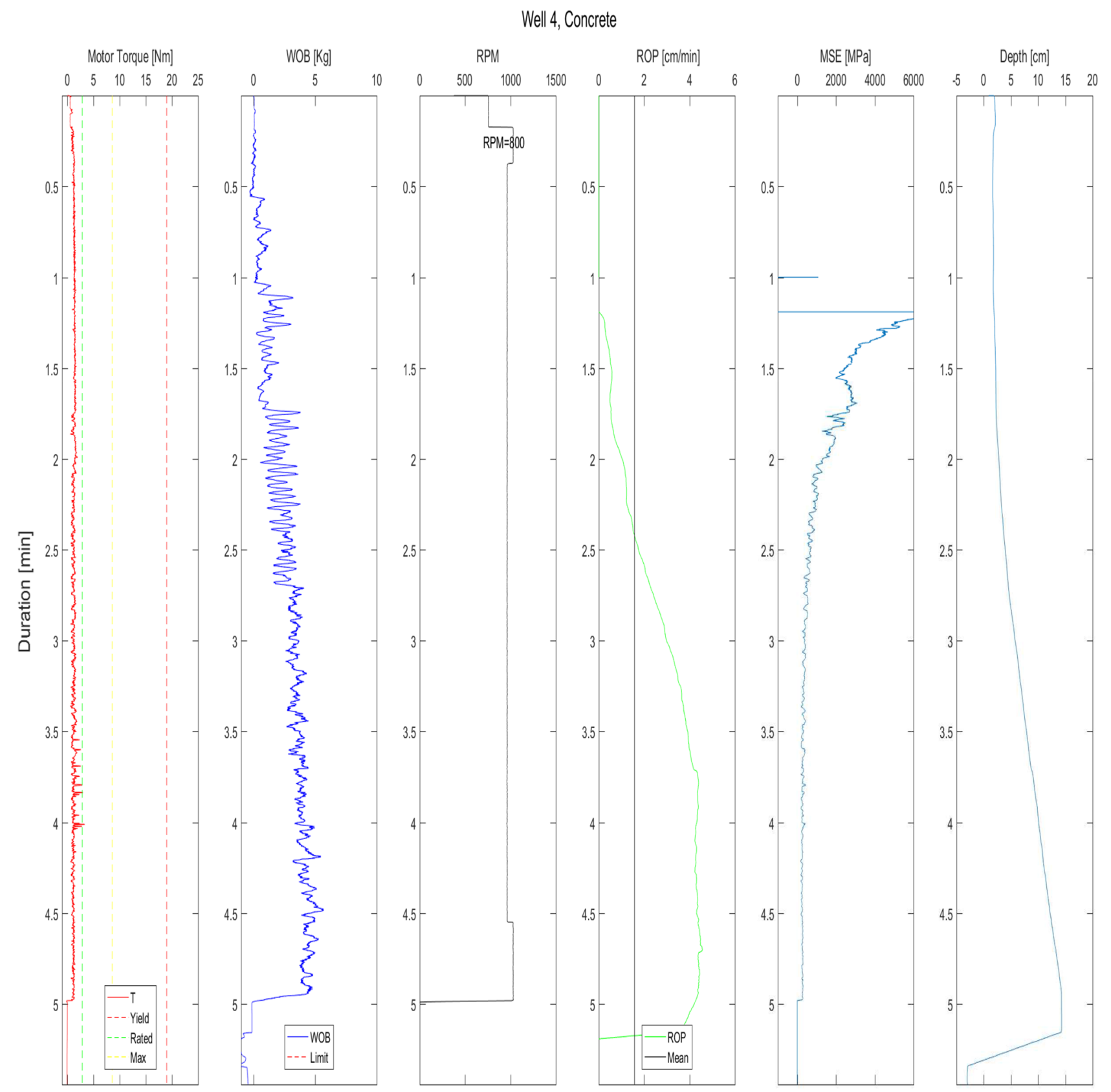

Fig. 13 Well Concrete 4, manual mode with varying WOB $($ RPM = 960)

ROP, the system started increasing the WOB and we can observe the ROP quickly increase, see Fig. 14. At this point, the system kept increasing both the RPM and the WOB based on the ROP optimization algorithm. According to the designed algorithm, if any drilling incidents occur, the system will respond accordingly, for example to shut down the system and start diagnosing the root-causes. During this test, no incidents occurred, which is not too surprising as it is a uniform test sample.

\section{Discussions}

All experiments conducted for the ROP optimization gave valuable information about searching optimal drilling parameters and occurring incidents for different formations. In chalk, we experienced incidents like bit balling and lateral vibrations. For incidents like bit balling, a more powerful pump might be needed. The lateral vibrations are mainly a mechanical problem. The downhole motor is a possibly good solution to measure vibrations. More 
Well 5 , Concrete

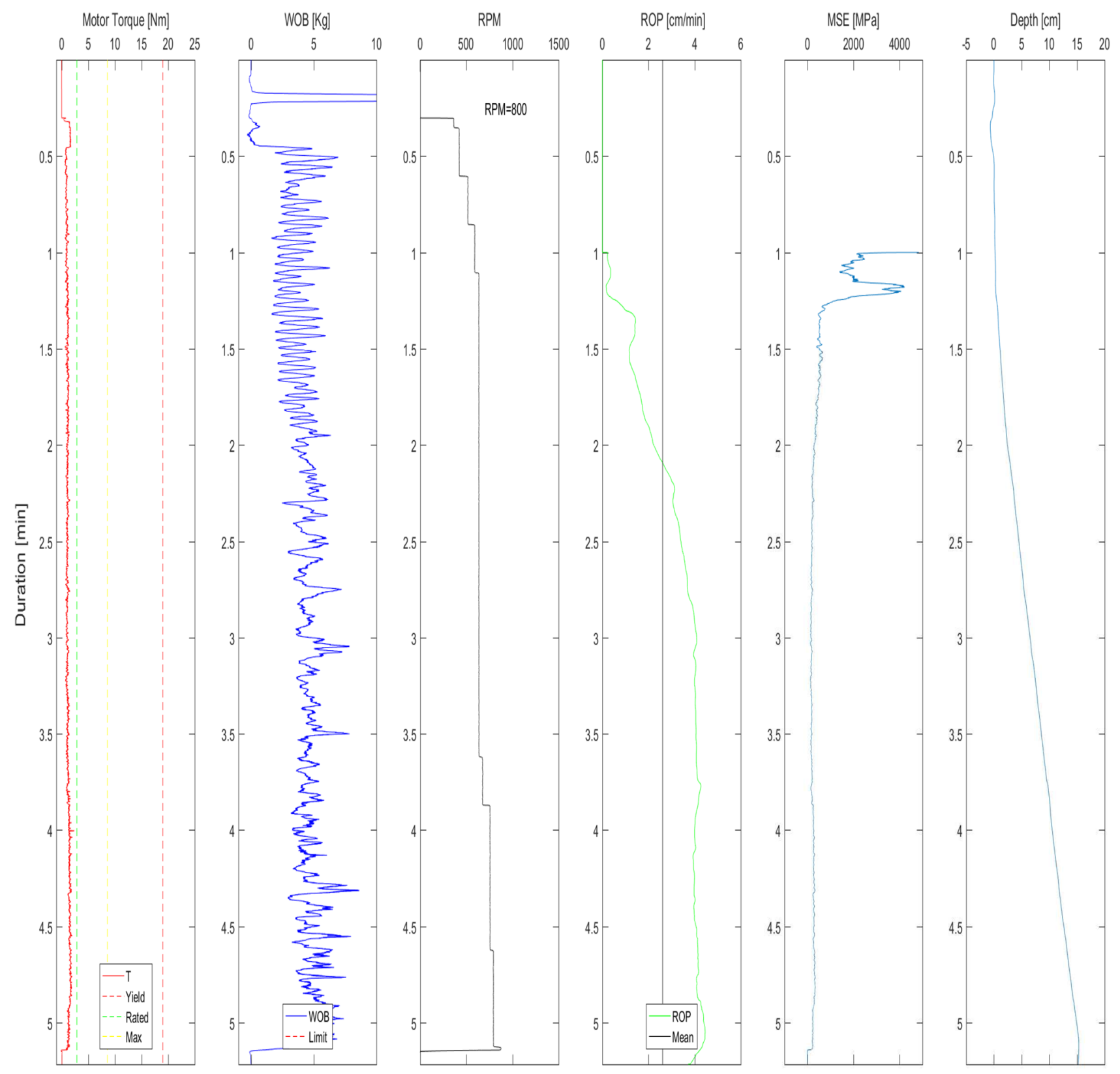

Fig. 14 Well Concrete 5, autonomous mode

research work on drill string vibrations is needed to be further investigated.

Drilling concrete was quite successful where no particular incident occurred. The challenge we experienced was software-wise regarding set-points given in PID controller and measured values on both the RPM and the WOB. We observed some deviations from the input values and measured values. A proposed solution is to have a better tuned PID controller, reduce vibrations and improve mechanical designs on key components. The optimal drilling parameters are presented in Table 4.

As mentioned, the low MSE indicates good drilling efficiency. Good drilling efficiency is the result of a large portion of the input energy used for drilling. If the MSE is high, one can expect a lot of vibrations and the diameter of the hole might be much larger than the drill-bit diameter. 
Table 4 Highest measured ROP with corresponding MSE, RPM and WOB. Lowest measured MSE with corresponding ROP

\begin{tabular}{lllll}
\hline Formation & $\mathrm{ROP}_{\max }(\mathrm{RPM}, \mathrm{WOB})$ & $\mathrm{MSE}_{\max }(\mathrm{MPa})$ & $\mathrm{MSE}_{\text {lowest }}(\mathrm{MPa})$ & $\begin{array}{l}\mathrm{ROP}_{\mathrm{MSE}_{\text {lowst }}} \\
(\mathrm{cm} / \mathrm{min})\end{array}$ \\
\hline Concrete & $4.454 \mathrm{~cm} / \min (794,5.69 \mathrm{~kg})$ & 240 & 140 & 4.1 \\
Chalk & $2.5 \mathrm{~cm} / \min (270,4 \mathrm{~kg})$ & 100 & 67.3 & 2.12 \\
\hline
\end{tabular}

\section{Conclusions}

Post-analysis of the data from drilling chalk and concrete highlights that higher rotational speeds do not necessarily equal to the higher rate of penetrations. Therefore, selecting a lower rotational speed to reduce the possibility of destructive incidents could be considered. The rigs optimization algorithms shall seek to find the optimal solution to avoid a potential incident and improve drilling efficiency by considering a multiobjective cost. For instance, reducing the MSE, improving the hole cleaning, reducing vibrations and drilling incidents while increasing the ROP.

From recent tests, our system drilled through uniform, soft through medium and hard formations at an impressive rate, with more than $4 \mathrm{~cm} / \mathrm{min}$ being drilled at certain parameters. Results show that there is a clear correlation between the low MSE and the high ROP, given minimal vibrations. A combination of precise control of operational parameters as the WOB and the RPM, with mechanical design upgrades, should yield better results. The implementation of the downhole sensor was one of the major upgrades. A strain gauge to measure the downhole WOB or torque can be used for evaluating drill string dynamics in order to mitigate vibrations. The weight measured by the surface load cells is not exactly the downhole WOB, but rather the surface load, which is affected by the axial vibrations experienced during drilling. Vibrations make it difficult to perfect real-time decisions for the WOB controller. Considering the accelerometer in the BHA, the accelerometer data are able to measure the amplitude of vibrations, especially lateral and torsional vibrations. Measurement of downhole vibrations which is able to act on detecting vibrations instantaneously and change drilling parameters accordingly is paramount for optimizing drilling performance. The resulting control system is capable of executing a series of control algorithms and models in parallel, such as the minimum MSE search (by gradient descent method), downhole vibrations, WOB and RPM control, incident detection and handling, and so on. Proof of concept has been obtained by the algorithms selecting optimal drilling set-points based on measured rig performance and response to earlier changes executed.

Acknowledgements Thanks go to NORCE for their support in helping to develop the rig and the agent. We also thank all the past and present members of the Drillbotics team at the University of Stavanger. We acknowledge Equinor academia program and Aker BP for funding the ongoing project.
Open Access This article is distributed under the terms of the Creative Commons Attribution 4.0 International License (http://creativeco mmons.org/licenses/by/4.0/), which permits unrestricted use, distribution, and reproduction in any medium, provided you give appropriate credit to the original author(s) and the source, provide a link to the Creative Commons license, and indicate if changes were made.

\section{References}

Akisanmi OA (2016) Automatic management of rate of penetration in heterogeneous formation rocks. Master's thesis, Universitetet i Stavanger

Ang KH, Chong G, Li Y (2005) PID control system analysis, design, and technology. IEEE Trans Control Syst Technol 13:559-576

Arnø M, Thuve A, Knoop S, Hovda S, Pavlov A, Florence F (2018) Design and implementation of a miniature autonomous drilling rig for drillbotics 2018. In: SPE/IADC International drilling conference and exhibition. Society of Petroleum Engineers, The Hague

ASM-Aerospace Specification Metals Inc. Aluminum 6061-t6; 6061-t651

Bilgesu H, Cox Z, Elshehabi T, Smith C, Idowu G, Florence F (2017) A real-time interactive drill-off test utilizing artificial intelligence algorithm for DSATS drilling automation university competition. In: SPE Western regional meeting. Society of Petroleum Engineers, Bakersfield

Bourgoyne AT (1986) Applied drilling engineering. SPE textbook series. Society of Petroleum Engineers, Bakersfield

Drillbotics. Guidelines 2017-2018

Godhavn JM, Hauge E (2018) Drilling automation-some industrial challenges and solutions. In: Fourth international colloquium on nonlinear dynamics and control of deep drilling systems

Godhavn J-M, Pavlov A, Kaasa G-O, Rolland NL (2011) Drilling seeking automatic control solutions. IFAC Proc Vol 44:10842-10850

Hu Q, Qingyou L (2006) Intelligent drilling: a prospective technology of tomorrow. In: International oil and gas conference and exhibition. Society of Petroleum Engineers, Beijing

Løken E, Trulsen A, Holsaeter AM, Wiktorski E, Sui D, Ewald R (2018) Design principles behind the construction of an autonomous laboratory-scale drilling rig. IFAC-OOGP 51:62-69

Løken E, Geekiyanage S, Sui D (2019) Small-scale autonomous drilling development for drilling digitalization. Oil Gas Eur Mag

Losoya EZ, Gildin E, Noynaert SF (2018) Real-time rate of penetration optimization of an autonomous lab-scale rig using a scheduled-gain PID controller and mechanical specific energy. IFAC-PapersOnLine 51:56-61

QuantumX. https://www.hbm.com/en/2128/quantumx-compact-unive rsal-data-acquisition-system/

Timoshenko SP, Gere JM (1961) Theory of elastic stability. McGrawHill, New York

Publisher's Note Springer Nature remains neutral with regard to jurisdictional claims in published maps and institutional affiliations. 